\section{AL-AZHAR}

Assiut Dental Journal
The Official Publication of The

Faculty of Dental medicine.

Al-Azhar Assiut Uniuersity.

AADJ, Vol. 3, No. 2, October (2020) - PP. 89:97

ISSn 2682-2822

\title{
The Shrinkage Pattern of Odontogenic Cyst After Surgical Decompression
}

\author{
Islam k. Mousa*1, Ahmed M. Adawy ${ }^{2}$
}

Codex : 11/2020/10

Aadj@azhar.edu.eg

\section{KEYWORDS}

Odontogenic, Cyst,

Decompression, 2D-Panorama,

Volumetric Measurement

1. B.D.S, 2012 G, Faculty of Dental Medicine, Boys, Cairo Al-Azhar University, Dentist, Ministry of Health.

2. Professor, department of Oral and Maxillofacial Surgery, Faculty of Dental Medicine, Boys, Cairo Al-Azhar University.

* Corresponding Author e-mail: dr.islam97@azhar.edu.eg

\begin{abstract}
Aim: This study was designed to evaluate the shrinkage pattern of odontogenic cyst after surgical decompression clinically and radiographically. Subjects and Methods: Twenty-eight patients were selected from those attending the outpatient clinic of the Department of Oral and Maxillofacial Surgery, Sayed Galal University Hospital with cystic lesions, larger than $3 \mathrm{~cm}$ on 2D-Panorama. Clinical examination was made to all patients as: Facial disfigurement, Intra-oral swelling and Sinus tract. Preoperative and after 3, 6 months postoperatively cone beam CT for every patient to determine extension of the cystic lesion, Proximity to the vital structures, Multi or uni-cystic lesion and Volumetric measurement of cystic lesion. All readings were recorded and analyzed statistically. Results: The mean volumetric analysis was $21.21 \pm 7.69 \mathrm{~cm} 3$ at base line (pre surgery), $13.96 \pm 5.25 \mathrm{~cm} 3$ after 3 months and $8.80 \pm 4.03 \mathrm{~cm} 3$ after 6 months which was statistically significant. Conclusion: Decompression is an effective treatment of odontogenic cysts, leading to a high percent reduction of the lesion area.
\end{abstract}

\section{INTRODUCTION}

Odontogenic cysts are one of the most common pathologic lesions in oral and maxillofacial region. They arise from proliferation of the odontogenic cell rests such as the epithelial cells of Malassez and cell rests of Serres in jaws. ${ }^{(1,2)}$ These pathologic lesions are slow-growing and noninvasive in most cases. Odontogenic cysts are benign pathologic lesions; however they may cause some serious problems such as tooth mobility or jaw fracture. These important complications can be due to the late diagnosis of cysts because of their slow and stealthy progression. ${ }^{(3,4)}$

The choice of treatment may be determined by some factor such as the extension of the lesion, relation with adjacent vital structures, evolution, origin, clinical characteristic of the lesion, cooperation and systemic condition of the patient. ${ }^{(5)} \mathrm{A}$ surgical procedure like enucleation of a large cyst can result in complications like hemorrhage, 
pain, swelling, ecchymosis, Infection, formation of an oro nasal communication, fistula or damage of adjacent nerve. ${ }^{(6)}$

In contrast the decompression is the standard contemporary procedures performed in large cystic lesions irrespective of age group and gender. It is a surgical technique by which a window is produced in the wall of the cyst to relieve the intracystic pressure and enable the cavity to decrease slowly in size. Later, when sufficient bone has been deposited and the adjacent vital structures have been saved from damage, complete enucleation can-be performed as a second-stage procedure. ${ }^{(7-10)}$ However, quantitative measurement of reduced volume after decompression among different cystic cavities has not been fully investigated. ${ }^{(11)}$ Although panoramic radiographs are helpful for the diagnosis of cystic lesions, they cannot be used to measure the volume of the cystic zone. Three-dimensional computed allows precise and reliable diameter, volume measurements, reproduction of borders of the lesion and displaced teeth and shows relations between the lesion and vital organ and anatomic structures. ${ }^{(12)}$

The rationale of the present study is to assess the rate of shrinkage following decompression of odontogenic cysts through three dimensional analysis.

\section{AIM OF THE STUDY}

The aim of the present study was to the shrinkage pattern of odontogenic cyst after surgical decompression

\section{PATIENT AND METHODS}

The study included twenty-eight patients (14 males and 14 females) with ages ranged from 6 to 35 years. Patients were selected from those attending the outpatient clinic of the Department of Oral and Maxillofacial Surgery, Sayed Galal University Hospital with asymptomatic cystic lesions, larger than $3 \mathrm{~cm}$ on 2D-Panorama.

\section{Selection criteria:}

- Inclusion criteria: Patient diagnosed with large odontogenic cyst, measuring more than $3 \mathrm{~cm}$. on panoramic $\mathrm{x}$-ray.

- Exclusion criteria: Small cystic lesions amenable to enucleation (less than $3 \mathrm{~cm}$ ), a histologically confirmed diagnosis of tumors such as Keratocystic odontogenic tumor (KCOT), mentally retarded and un-cooperative patients.

\section{A -Preoperative phase}

All patients underwent pre-operative clinical examination: Patients' data were collected; name, gender and age, medical and dental histories were taken, Facial disfigurement, Intra-oral swelling and Sinus tract. Also, all patients underwent standardized panoramic x-ray to determine the affected region and to confirm that the lesion is larger than $3 \mathrm{~cm}$. Preoperative cone beam CT for every patient to determine extension of the cystic lesion, Proximity to the vital structures, Multi or uni-cystic lesion and Volumetric measurement of cystic lesion. Fig. (1)

\section{B -Operative phase}

Bracket attachment: Before surgery, orthodontic brackets were attached to adjacent teeth of the planned surgical site (minimum of two teeth). These brackets were used for fixation of the decompression tube with stainless steel ligature wires

Premedication: One hour before surgery, patients were instructed to take a pre- operative dose of broad spectrum antibiotic Megamox (Jazeera Pharmaceutical Industries - Saudi Arabia. Imported by El Hekma Company) tablets 1g. (Amoxicillin + Clavulanate Potassium). For children Megamox suspension 60:90 mg per $\mathrm{kg}$ /day was prescribed. Antibiotics were continued every 12 hours during the postoperative course for 5 days. 


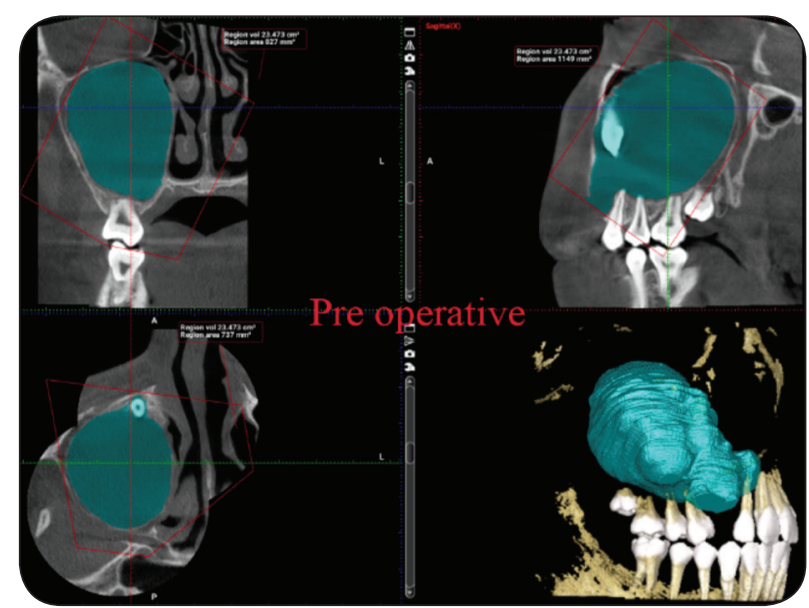

Fig. (1) Preoperative CBCT showing extension of the cystic lesion, Proximity to the vital structures, uni-cystic nature of the lesion and Volumetric measurement of cystic lesion.

Anaesthesia: The surgery was performed under local anesthesia and in children who were difficult to manipulate, general anesthesia was employed.

Local anesthesia was achieved through maxillary nerve block or inferior alveolar nerve block techniques by using $4 \%$ articaine (Artinibsa TM articaine (hydrochloride + epinephrine) $40 \mathrm{mg} /$ $0.01 \mathrm{mg} / \mathrm{ml}$, Spain) with 1:100,000 epinephrine.

General anesthesia was administered through induction, maintenance, and recovery phases. Intravenous line was started and endotracheal tube was inserted to secure the air way. Induction phase was done by using hypnotic (Thiopental sodium, 3-7mg $\mathrm{kg}$ ) and muscle relaxant (Nimbex, 0.1-0.15mg $\mathrm{kg}$ (GlaxoSmithKline, Elsalam City, Egypt). Maintenance phase was intitated by inhalation (forane 0.5$1.0 \% \mathrm{~kg}$ - Al kahira, Pharma. \&Chemo. Ind, Co.Cairo, Egypt). while recovery phase was achieved by a reverse agent (neostigmine $0.5-2 \mathrm{mg} \backslash \mathrm{kg}$ - Amoun, ElObour City,Cairo, Egypt) and (atropine $0.5-1.0 \mathrm{mg}$ kg- Misr, Co.for Pharma. Ind. S.A.E).

The surgical field was disinfected by betadine (Povidone-iodine, Mundipharma international-Nile pharma) and the patient was draped with sterile towels leaving only the prepared site exposed.
Surgical procedure: Decompression was performed by creating an opening (a hole) through the mucosa, submucosa and bone surface into the lesion. The hole performed was large enough for taking an incisional biopsy of the cystic lining. The pathological cavity was aspirated and thoroughly irrigated with saline.

A polyethylene tube was perforated with a needle, and a stainless steel ligature wire inserted into these perforations. The tube was inserted into the created hole allowing for daily irrigation along the follow up periods. The tube was fixed in its place by stainless steel ligature wires which were attached to the orthodontic brackets on the adjacent teeth. Simple interrupted sutures using vicryl suture material was used to close the wound edges around the tube. The tube was replaced or cleaned if it becomes obstructed. In all cases, tissue biopsy was sent for histopathological examinations.

\section{C- Postoperative phase}

\section{Postoperative medications:}

Patients were instructed to take a postoperative medical regimen containing the following: Nonsteroidal anti-inflammatory drug (For Adult Ibuprofen tablet 1200 to $3200 \mathrm{mg} /$ day in divided doses every 6-8 hours for 2 days- Ibuprofen, Kahira Pharmaceuticals \& Chemical industries Co., Cairo, Egypt). (For children Ibuprofen suspension $20 \mathrm{mg}$ per $\mathrm{kg} /$ day, in divided doses every $6-8$ hours for 2 days) to relief pain.

Broad spectrum antibiotic (For Adult Megamox tablets $1 \mathrm{~g}$. every 12 hours for 5 days). (For children Megamox suspension 60:90 mg per kg/day, in divided doses every 12 hours for 5 days) as a prophylactic measure against any possibility of infection.

\section{Postoperative instructions:}

To minimize swelling, the patient was instructed to use cold fomentations on the face over the site of surgery for 20 minutes on, 20 minutes off, for 24 hours. Then, switch to a warm moist fomentations on the swelling for 20 minutes in each hour for a 
week. The patient was instructed to irrigate the cystic space with normal saline at least two times daily through the tube and recalled periodically for follow-up. Gently brush all your teeth, to prevent food build up and take care not to disturb the surgical site.

\section{D- Follow up phase}

\section{Clinical evaluation}

The $1^{\text {st }}$ visit after the operation was scheduled after 3 days for checking of the site of surgery and assure that patients have followed the instructions.

The second visit was scheduled one week after surgery to remove the suture.

All patients were evaluated clinically at (one, two \& three weeks, one, two and six months) postoperatively for the following: Regular recall for irrigation and check healing around and plugging of the decompression tube, infection and intraoral swelling.

\section{Radiographic evaluation:}

All patients were examined radiographically with a cone beam C.T 3 and 6 months post-operatively to assess the rate of shrinkage of the cyst after surgical decompression.

After completion of the planned decompression 6 months interval, the patients were prepared for enucleation of the decompressed cyst.

\section{Statistical analysis:}

Data were represented as mean and standard deviation. Repeated measures analysis of variance (ANOVA) test was used to compare numeric variables within the studied group of patients. Post Hoc test was done if ANOVA or Friedman tests were positive. Using SPSS version in all tests, result was considered statistically significant if the $\mathrm{p}$ - value was less than 0.05 .

\section{RESULTS}

Twenty-eight patients ranged in age between 6.0-35.0 years with a mean age of $17.0 \pm 9.80$ years were included in the present study. Selected patients were 14 males and 14 females. They had 16 maxillary and 12 mandibular cysts. Patients had 16 dentigerous and 12 inflammatory cystic lesions.

The mean volumetric analysis was $21.21 \pm 7.69$ $\mathrm{cm}^{3}$ at base line (pre surgery), $13.96 \pm 5.25 \mathrm{~cm}^{3}$ after 3 months and $8.80 \pm 4.03 \mathrm{~cm}^{3}$ after 6 months. The percentage of reduction for volumetric analysis was $33.75 \pm 19.11 \%$ in the first 3 months and was $24.77 \pm$ $8.82 \%$ in the second 3 months with total shrinkage $58.52 \pm 16.05 \%$. There is a negative correlation between $\%$ of reduction for volumetric analysis and the age of the patients. Mandibular cystic lesions showed higher reduction rate in volume than in the maxillary cystic lesions. Inflammatory cysts showed a higher reduction rate in volume than dentigerous cysts. Female cysts showed a higher reduction rate in volume than male cysts.

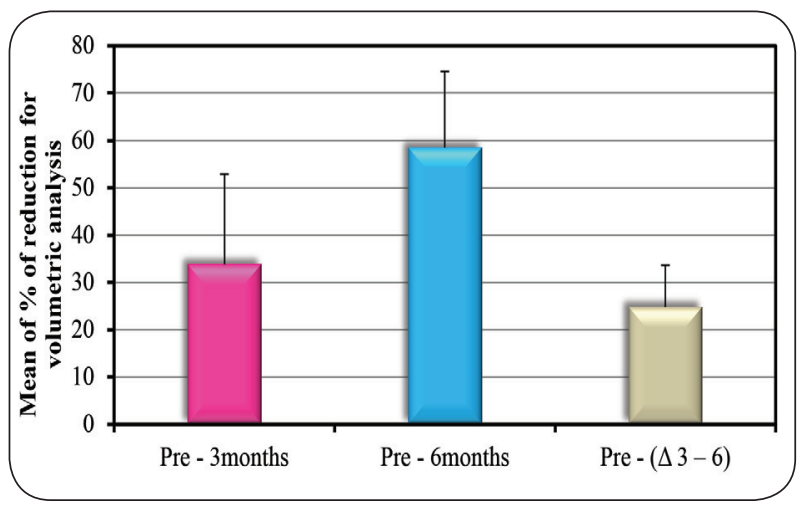

Fig. (2) Bar chart showing the Comparison between the different time periods according to $\%$ of reduction for volumetric analysis.

\section{DISCUSSION}

Various treatment methods have been used for the management of large odontogenic cysts but none is widely accepted. ${ }^{13}$ Treatment options have included, enucleation alone, marsupialization and decompression. ${ }^{14}$ Enucleation comprises the 
complete removal of the cyst lining. This is usually a definitive treatment and requires no further surgical intervention but in large cystic lesions, enucleation might be radical and harmful because of possible damage to adjacent vital structures. ${ }^{7}$

Marsupialization and decompression are widely used techniques for primary or definitive treatment of extended odontogenic cysts, preventing damage to important anatomical structures and reducing the surgical trauma with no necessity for grafting. Marsupialization is a surgical procedure in which the supra-wall of the cyst is removed and the internal wall of the cyst is sutured with the oral mucosa so that part of the lining epithelium can be transitioned into the oral epithelium. With decompression, the aim has been to reduce the size of the lesion by inserting a rubber tube or a stent through a small hole into the cyst. ${ }^{15}$

Decompression is a noninvasive, well-tolerated procedure. It was easily and rapidly performed in a dental office under local anesthesia. Drawbacks of these procedures are the need for patients' cooperation, as they must irrigate the cystic cavity for several weeks and undergo frequent follow-up visits. ${ }^{14,16}$ With regard to the operative technique, the same decompression protocol was applied in all cases of the present study. As has been previously noted, the technique proved to be more conservative and to limit intraoperative and postoperative patient discomfort complications. ${ }^{14,17}$

Nevertheless, many points remain to be clarified. To date, there has been no standardization of the parameters of volume reduction, and consequently, the actual percentage of volume decrease is unclear. Furthermore, the possible relationships between this parameter and the duration of decompression or other variables, including sex, age and the histological type, size and location of the cysts, have not been determined.

Various devices have been described in the literature to maintain the opening after marsupialization or decompression. Pogrel ${ }^{18}$ and August et al. ${ }^{19}$ used a shortened nasopharyngeal tube sutured to the mucosal window in the posterior part of the mandible and iodoform gauze packing impregnated with bacitracin ointment in the maxilla. Others reported good results with an obturator or stent made of acrylic resin, which allowed patients to rinse the cavity by inserting a syringe through its lumen. ${ }^{9,20,21}$ Acrylic stents can be custom made by a dental technician to correspond to the width of the opening and exact distance between the mucosal surface and the cystic lining. ${ }^{20}$ Tolstunov $^{22}$ applied intravenous administration sets or nasal $\mathrm{O} 2$ cannulas cut to the appropriate size.

In the present study, a new method to maintain the opening after decompression was used. A polyethylene tube was used which allowed for daily irrigation and prevented the retention of large particles of food. The tube was perforated with a needle, and a stainless steel ligature wire inserted. Orthodontic brackets were attached to the adjacent, cleaned teeth and secured the wire to them. Orthodontic brackets cause less damage to the gingival tissues than wires or sutures around the fenestration or the teeth. The wires can be easily detached, the length or position of the tube adjusted and the tubing can be replaced or cleaned if it becomes obstructed. The utilization of orthodontic brackets was firstly introduced by Zhu et al. ${ }^{23}$ to the best of our knowledge, there are no controlled studies in the literature comparing these materials regarding the percentage of reduction of the lesioned area.

Radiography is the most commonly used method for detecting bone formation in healing osseous defects. 7, 8, 24 Panoramic radiograph is the most common imaging system used by dentists, oral and maxillofacial surgeons for routine evaluation of the dento-alveolar complex. Although panoramic radiograph is useful to obtain an overview of the dento-alveolar complex, there are some limitations, such as magnification and distortion, which make such measurements inaccurate. ${ }^{14,}{ }^{23}$ Cone beam computed tomography (CBCT) techniques are the 
best method of obtaining minimally invasive and accurate volumetric measurements, because of their reproducibility and high degree of reliability. ${ }^{14,25}$ Moreover, CBCT delivers much lower doses of radiation to patients than fan-beam CT systems. ${ }^{26}$

The present study aimed to evaluate the shrinkage pattern of odontogenic cyst after surgical decompression in large odontogenic cystic lesions. In the present study, decompression was used when cystic lesions exceeded $3 \mathrm{~cm}$ before enucleation similar to Enislidis et a ${ }^{20}$. Effects of decompression were evaluated using 3D-CT and using Planmeca ProMax ${ }^{\circledR}$ 3D Max unit with $3 \mathrm{D}$ reconstruction software.

In the present study, all lesion volumes were measured at standard intervals (preoperatively, 3 and 6 months postoperatively). This method provided standard measurement of the shrinkage rate of large odontogenic cysts.

Dimensional reduction seems to be strictly correlated with the duration of treatment. Three months after surgery, volume decreased from $21.21 \pm 7.69 \mathrm{~cm}^{3}$ to $13.96 \pm 5.25 \mathrm{~cm}^{3}$, then further decreased after 6 months and reached $8.80 \pm 4.03 \mathrm{~cm}^{3}$.

Enislidis et al ${ }^{20}$ reported that the mean decrease of cystic lesions was $81 \%$ in postsurgical follow up phase. Anavi et $\mathrm{al}^{27}$ reported that the lesion area decreased by a mean of $79.3 \%$ in a mean of $9.2 \pm 5.2$ months. Lizio et al ${ }^{14}$ reported $49.86 \%$ decrease in a mean of 5.7 months, which is consistent with the findings of the present study (lesion area decreased by a mean of $58.52 \%$ in 6 months).

There was a statistically significant change in mean volumetric analysis through all periods. The mean $\%$ of shrinkage in volume in the first interval (before surgery to 3 months after surgery) 33.75 $\pm 19.11 \%$. The second interval (3 to 6 months postoperative) showed a shrinkage of $24.77 \pm 8.82$. The overall shrinkage was $58.52 \pm 16.05 \%$.
Although the period of decompression is traditionally about $6-14$ months. ${ }^{[7,9,14,27]}$ the range reported in the literature is from 2 to 80 months ${ }^{[9,27]}$. Other authors considered 3 months sufficient for significant cyst volume reduction ${ }^{[14]}$.

The main principle of decompression has been to release of intraluminal pressure and to allow the bone cavity of a cystic lesion to progressively decrease in volume, with the gradual growth of surrounding bone. Based on this, it was the decision made in the present study that a 6 months waiting time was enough to safely proceed with enucleation. Considering the fact that most of the shrinkage observed was accomplished during the first 3 months after the decompression, it is reasonable to conclude that a considerable amount of shrinkage had already been attained during the follow-up period in this study.

However, in spite of the short duration of decompression, it was quite enough to at least fulfill the minimum and most crucial goal: the size of the lesion was reduced enough to be enucleated without damaging the adjacent tissue.

However, in spite of the short duration of decompression, it was quite enough to at least fulfill the minimum and most crucial goal: the size of the lesion was reduced enough to be enucleated without damaging the adjacent tissue.

The effect of patient age on the rate of decrease of the lesion has been a controversial issue. Lizio et $\mathrm{al}^{14}$, Gao et al, ${ }^{28}$ and Kubota et al ${ }^{29}$ found no correlation between age and rate or speed of shrinkage. In contrast, Park et al, ${ }^{11}$ and Anavi et al, ${ }^{27}$ suggested a correlation between age and the rate of decrease of lesions, which supports the findings of the present study. There was a negative correlation between $\%$ of reduction for volumetric analysis and age of the patients. It seems logic to assume that the velocity of shrinkage was faster when the patient was younger. 
Oliveros et al., ${ }^{30}$ found that the decompression of mandibular lesions have a higher reduction rate than maxillary lesions. This observation supports the findings of the present study. Mandibular cysts decreased by a mean of $70.81 \%$ in 6 months, whereas maxillary cysts decreased by $49.30 \%$ in the same time.

Regarding the histopathologic typing of the cystic lesions, Kim and Lee ${ }^{15}$ reported that dentigerous cysts have a higher percentage of reduction rate than inflammatory cysts after decompression. In contrast, Kubota et al. ${ }^{29}$ and Anavi Y et al. ${ }^{27}$ found that the analysis by histologic type yielded a slightly lower percentage of reduction of dentigerous cysts $(81.52 \%)$ than inflammatory cysts $(85.64 \%)$. Although wider range of difference was calculated, similar trend was observed in the present study. Dentigerous cysts decrease by a mean of $50.91 \%$ in 6 months whereas inflammatory cysts decreased by $68.67 \%$ in the same time.

Considering the gender of the patients, Sun-Tae Lee et al. ${ }^{31}$ found that reduction rate in females was higher than males. This finding goes parallel with the present observation that females have a higher rate of reduction than that of male patients. In females, cysts decreased by a mean of $60.77 \%$ in 6 months whereas in males, the cysts decreased by $56.28 \%$ in the same time

\section{CONCLUSION}

This study concluded that decompression is an effective treatment of odontogenic cysts, leading to a high percent reduction of the lesional area. Dimensional reduction seems to be strictly correlated with the duration of treatment. Polyethylene tube secured with orthodontic brackets is simple and safe method to maintain the opening, and to allow daily irrigation of the cystic cavities. There was a negative correlation between the rate of volume reduction and age of the patients. Decompression of mandibular lesions resulted in a higher reduction rate than did maxillary lesions. Inflammatory cysts have a higher percentage of reduction rate than dentigerous cysts after decompression. Volumetric reduction rate of the cystic lesions was higher in females than males following decompression.

\section{REFERENCES}

1. Slootweg P. Lesions of the jaws. Histopathol. 2009; 54:401-18.

2. Regezi A. Odontogenic cysts, odontogenic tumors, fibro osseous and giant cell lesions of the jaws. Mod Pathol. 2002; 15:331-41.

3. Sumer M, Bas B, Yildiz L. Inferior alveolar nerve paresthesia caused by a dentigerous cyst associated with three teeth. Oral Medicine, Oral Pathol and Oral Surgery Med Oral Patol Oral Cir Bucal. 2007; 12: 388-90.

4. Matise J, Beto L, Fantasia J, Fielding A. Pathologic fracture of the mandible associated with simultaneous occurrence of an odontogenic keratocyst and traumatic bone cyst. J Oral Maxillofac Surg. 1987; 45:69-71.

5. Domingos R. Surgical approaches of extensive Periapical cyst. Considerations about Surgical technique. 2004; 23 : 317-28.

6. George V. Thomas G, Kuttappa M, Govind G. Management of a large periapical cyst (apical matrix \& surgical complications) - A case report. Endodontol. 2009; 10:84-9.

7. Zhao Y, Liu B, Han Q, Wang S, Wang Y. Changes in Bone Density and Cyst Volume After Marsupialization of Mandibular Odontogenic Keratocysts (Keratocystic Odontogenic Tumors). J Oral Maxillofac Surg. 2011; 69:1361-66.

8. Bodner L, Bar-Ziv J: Characteristics of bone formation following marsupialization of jaw cysts. Dentomaxillofac Radilo. 1998; 27:166-69.

9. Nakamura N, Mitsuyasu T, Mitsuyasu Y. Marsupialization for odontogenic keratocysts: Long-term follow-up analysis of the effects and changes in growth characteristics. Oral Surg Oral Med Oral Pathol Oral Radiol Endod. 2002; 94:543-48.

10. Ninomiya T, Kubota Y, Koji T. Marsupialization inhibits interleukin-1 expression and epithelial cell proliferation in odontogenic keratocysts. J Oral Pathol Med.2002; 31:526-31.

11. Park H, Song I, Seo B, Lee J, Kim M. The effectiveness of decompression for patients with dentigerous cysts, keratocystic odontogenic tumors, and unicystic ameloblastoma. J Korean Assoc Oral Maxillofac Surg. 2014; 40: 260-65. 
12. Asutay F, Atalay Y, Turamanlar O. Three-Dimensional Volumetric Assessment of the Effect of Decompression on Large Mandibular Odontogenic Cystic Lesions. J Oral Maxillofac Surg. 2016; 74: 1159-66.

13. Abdullah WA: Surgical treatment of keratocystic odontogenic tumour: A review article. Saudi Dent J .2011; 23:61-5.

14. Lizio G, Sterrantino A, Ragazzini S and Marchetti C. Volume reduction of cystic lesions after surgical decompression: a computerised three-dimensional computed tomographic evaluation. Clin Oral Invest 2013; 17:1701-8.

15. Kim M, Chung W, Cha H and Nam W. Normal eruption guidance of unerupted permanent teeth associated with dentigerous cyst by decompression: 5 cases report. J Korean Assoc Oral Maxillofac .Surg 2009; 35:271-5.

16. Pogrel MA: Decompression and marsupialization as definitive treatment for keratocysts - A partial retraction. J Oral Maxillofac Surg. 2007; 65:362-3.

17. Liang YJ, HeWJ, Zheng PB, et al: Inferior alveolar nerve function recovers after decompression of large mandibular cystic lesions. Oral Dis .2015; 21:674-8.

18. Pogrel AN. Treatment of keratocysts: the case for decompression and marsupialization. J Oral Maxillofac Surg .2005; 63:1667-3.

19. August M, Faquin WC, Troulis MJ, Kaban LB. Differentiation of odontogenic keratocyst epithelium after cyst decompression. J Oral Maxillofac Surg .2003; 61:678-83.

20. Enislidis G, Fock N, Sulzbacher I, et al. Conservative treatment of large cystic lesions of the mandible: A prospective study of the effect of decompression. Br J Oral Maxillofac Surg. 2004; 42:546-50.

21. Kaban LB, Troulis MJ, editors. Pediatric oral and maxillofacial surgery. Philadelphia: Saunders .2005; 34: 823-33.

22. Tolstunov L. Marsupialization catheter. J Oral Maxillofac Surg .2008; 66:1077-9.
23. Zhu F, Huang S, Chen Z, Li W, Zhang D. New method to secure cyst decompression tube in tooth-bearing areas. $\mathrm{Br} \mathrm{J}$ Oral Maxillofac Surg. 2017; 55:200-1.

24. Chiapasco M, Rossi A, Motta J et al .Spontaneous bone regeneration after enucleation of large mandibular cysts: a radiological computed analysis of 27 consecutive cases. J Oral Maxillofac Surg. 2000'58:942-9.

25. Suomalainen A, Esmaeili E, and Robinson S. Dentomaxillofacial imaging with panoramic views and cone beam CT. Insights Imaging. 2015; 6:1-16.

26. Schulze D, Heiland M, Thurmann H, Adam G. Radiation exposure during midfacial imaging using 4 and 16-slice computed tomography: cone beam computed tomography systems and conventional tomography. Dentomaxillofac Radiol .2004; 33:83-6.

27. Anavi Y, Gal G, Miron H, Calderon S and Dror M. Decompression of odontogenic cystic lesions: clinical long-term study of 73 cases. Oral Surg Oral Med Oral Pathol Oral Radiol Endod .2011; 112:164-9.

28. Gao L, Wang X, Li S, Liu C, Chen C, Li J, Yan X, Zhang , Ren W, Zhi K. Decompression as a Treatment for Odontogenic Cystic Lesions of the Jaw. J Oral Maxillofac Surg.2014; 72:327-33.

29. Kubota Y, Imajo I, Itonaga R, et al: Effects of the patient's age and the size of the primary lesion on the speed of shrinkage after marsupialisation of keratocystic odontogenic tumours, dentigerous cysts, and radicular cysts. Br J Oral Maxillofac Surg .2013;51:358-62.

30. Oliveros L, Fernández A, Torres D, Serrera A, Castillo R, Segura J, Gutiérrez L. Reduction rate by decompression as a treatment of odontogenic cysts. Med Oral Patol Oral Cir Bucal. 2017; 22:635-42.

31. Sun L, Su K, Seong M, Ji O, Jae Y, and Jae K. The effect of decompression as treatment of the cysts in the jaws: retrospective analysis. J Korean Assoc Oral Maxillofac Surg. 2017; 43: 83-7. 


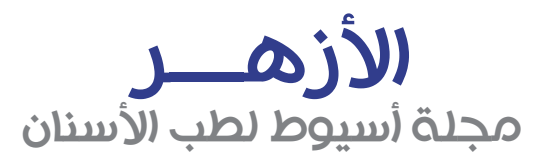

النشر الرسمي لكلية طب الأسنان جامعة الأزهر أسيوط الكاية

\title{
تقييم نمط الانكماش للكيس السنص بعد تخفيف الضغط جراحيا
}

\author{
اسلام كمال حسن موسى , احمد محمد العدوى
}

1. قسـم جراحة الفهم والوجـه والفكين، كلية طب الاسـنان، ( القاهرة ربنين)، جامعة الازهر، مصر

DR.ISLAM 97@AZHAR.EDU.EG البريد الالكترونى للباحث الرئيسي: *

(الملخص :

الهدف: صممت هذه الدراسة لتقييم نمط الانكماش للكيس السنى سريريًا وإشعاعيًا بعد تخفيف الضغط جراحيا.

المواد والاسـاليب: ثمانية وعشرون مريضا تم اختيار هم من أولئك الذين يحضرون العيادة الخارجية لقسم جراحة الفم والوجه والفكين في

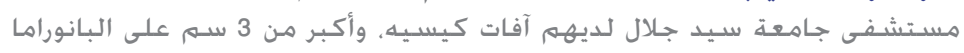

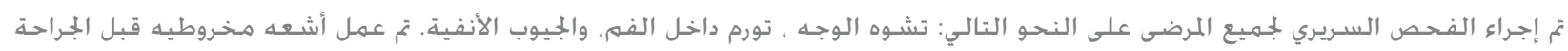

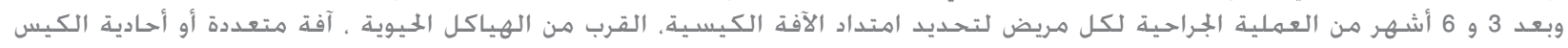

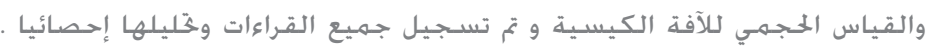

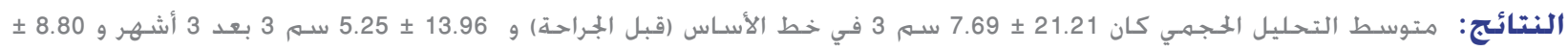
4.03 سـم3 بعد 6 أشهر والتي كانت ذات دلالة إحصائية.

الخخلاصة: تخفيف الضغط هو علاج فعال للتكيسات السنية ، ما يؤدي إلى تقليل نسبة عالية من منطقة الآفة الكلمات المفتاحية :سنى, كيس, تخفيف الضغط ,بانوراها ثنائية الابعاد , قياس حجمي 